\title{
Being First, Being Right, and Being Credible Since 2002: A Systematic Review of Crisis and Emergency Risk Communication (CERC) Research
}

\author{
Ann Neville Miller ${ }^{1}$ (D), Chad Collins ${ }^{1}$, Lindsay Neuberger ${ }^{1}$, Andrew Todd ${ }^{2}$, \\ Timothy L. Sellnow ${ }^{1}$, , and Laura Boutemen ${ }^{1}$ \\ 1. Nicholson School of Communication and Media, University of Central Florida, \\ Orlando, FL, USA \\ 2. University of Central Florida Libraries, University of Central Florida, Orlando, FL, USA
}

\begin{abstract}
The crisis and emergency risk communication (CERC) model is a five-stage theory that merges established public health practices with principles of crisis communication. Although CERC has been regularly applied on the ground, it has been criticized as lacking the coherence and unity necessary to serve as a framework for research. To determine the extent and type of research CERC has generated since its original presentation to the academic community 15 years ago, we conducted a systematic review of research using CERC as a theoretical lens. A total of 4,471 articles in 20 languages were screened, 400 full texts examined, and 19 articles included in the research and theory analysis, of which one tested tenets of the CERC model. We conclude that CERC has rarely been theoretically tested, and we argue that reformulation of the propositions is necessary for empirical support of the model to proceed.
\end{abstract}

KEYWORDS: crisis and emergency risk communication, CERC, crisis communication theory, systematic review

The crisis and emergency risk communication (CERC) model (Reynolds \& Seeger, 2005) is a five-stage theory that merges established public health practices with principles of crisis communication (Sellnow \& Seeger, 2013). Developed by the Centers

CONTACT Ann Neville Miller (D) · E-mail: Ann.Miller@ucf.edu • Nicholson School of Communication and Media • University of Central Florida • 12405 Aquarius Agora Drive • Orlando, FL 32816, USA 
for Disease Control and Prevention (CDC), CERC was part of a comprehensive effort to build capacity for crisis response among public health agencies (Veil et al., 2008). Within five years after the first CERC manual was published in 2002, the CDC had provided training to over 100,000 public health professionals through webbased and CD-ROM delivery as well as in face-to-face classrooms across the United States. The principles of CERC have been leveraged repeatedly to address such varied public health crises as Ebola (Kieh et al., 2017), bird flu (Vos \& Buckner, 2016), depleted uranium exposure (Cicognani \& Zani, 2015), winter storms (Rice \& Spence, 2016), and chemical spills (Thomas et al., 2016).

Although CERC has been regularly applied on the ground, it has been criticized as lacking the coherence and unity necessary to serve as a framework for research (Veil et al., 2008; Sellnow \& Seeger, 2013). Indeed, Reynolds and Seeger's (2005) original publication of CERC for academic audiences was not designed to be a presentation of theory, but a call to attend to a new type of communication need. Veil et al. subsequently attempted to provide a roadmap for empirical investigation of CERC, but we argue that their six propositions are actually underlying assumptions and are not readily testable. Although CERC itself is derived from grounded theory and situated within an extensive body of public health and crisis communication literature, the propositions need revision in order to be heuristically provocative. To our knowledge, no systematic investigation of research related to CERC has been undertaken since its inception. Thus, the degree to which it has, or has not, spawned research and furthered knowledge is not known. The purpose of the current study was to determine the extent and type of research CERC has generated since its original presentation to the academic community 15 years ago (Reynolds \& Seeger, 2005), and on the basis of those findings propose directions for theory advancement.

\section{Literature Review}

\section{Features of the CERC Model}

In their original presentation of CERC, Reynolds and Seeger (2005) merged two mature but distinct areas of communication 
research: risk and crisis communication. They described risk communication as a field typically involving messages about negative consequences of unhealthy behaviors, principally persuasive in nature, characterized by long-term and routine communication, and closely grounded in scholarship on fear appeals and behavior change. The impetus for risk communication messages is current scientific knowledge about a risk factor, knowledge that health communicators attempt to convey to affected publics. Crisis communication, in contrast, is usually associated with public relations; addresses events such as employee violence, toxic spills, or organizational crises; is short-term and primarily informative; and usually gives rise to broad public interest and media coverage, much of which may involve probing and even hostile questions about culpability. The catalyst for crisis communication is a current situation or event, and messaging may be just as much about disclosing what is unknown as what is known. Reynolds and Seeger argued that crisis and emergency risk communication was a new hybrid form of messaging that health-care agencies could not afford to ignore, and that CERC provided a comprehensive approach to emergency public health events.

CERC adopts a crisis development, or stage model, approach. Like stage models addressing disaster management (e.g., Fink, 1986; Turner, 1967, it attempts to aid practitioners with sensemaking by identifying a series of discrete phases of the unfolding of a crisis, irrespective of crisis type (Sellnow \& Seeger, 2013). That is, stage models define events that are by nature chaotic and difficult to interpret.

The distinctives of CERC are its division of public health crises into five stages and identification of communication strategies to implement at each point for effective response (Reynolds \& Seeger, 2005). The five stages are: (1) pre-crisis, (2) initial event, (3) maintenance, (4) resolution, and (5) evaluation (Reynolds \& Seeger, 2005). During the pre-crisis stage, a potential threat is detected, and communication activities focus on risk messages such as urging publics to prepare in case the identified threat evolves into a crisis event. The initial event involves the onset of a crisis and requires the dissemination of messages to reduce uncertainty, promote reassurance, and foster self-efficacy among the public and 
individuals affected by the crisis. Maintenance corresponds to the stage when the crisis unfolds, and messages serve a similar purpose as in the initial event stage, but they should provide more information about the crisis and correct any misperceptions held by the public. Resolution refers to the end of the crisis event. During this stage, communication to the public and affected individuals addresses restoration and rebuilding, but also honestly reports findings about factors that caused the crisis. Finally, the evaluation stage allows practitioners to reflect on the circumstances of the crisis and discuss lessons learned. This stage includes assessment of the communication activities that were undertaken before, during, and after the crisis (Reynolds \& Seeger, 2005).

CERC has been presented to practitioners in a series of manuals published by the U.S. Department of Health and Human Services. Guidance in these publications is encapsulated in six principles (US Department of Health and Human Services [HHS] and CDC, 2018):

1. be first (communicating information quickly is crucial);

2. be right (information can include what is known, what is not known, and what is being done to fill in the gaps);

3. be credible (honesty and truthfulness should not be compromised);

4. express empathy (acknowledge people's challenges and suffering in words);

5. promote action (giving people meaningful things to do calms anxiety and promotes self-efficacy); and

6. show respect (respectful communication engenders cooperation and rapport).

Like most stage models, CERC was generated from grounded theory, based on the experiences of myriad scholars and health communicators over several decades. Originating as it did from the practitioner-centric CDC, CERC was intended to be used by health communicators and emergency response personnel on the ground, and tested, if at all, in applied research. This applied orientation of CERC has been noted as one of its strengths (Elledge et al., 2008; Sellnow \& Seeger, 2013). Indeed, some scholars of crisis 
communication have argued that the primary objective of theorizing should be to work with practitioners to protect stakeholders from harm (Anthony \& Sellnow, 2011). Such "practical theory" should be "judged by whether it informed patterns of practice that made life better" (Barge \& Craig, 2009, p. 70). By this measure, CERC has been successful.

\section{Weaknesses of CERC as Theory}

Reynolds and Seeger's (2005) original article made no claim to theory status. Although they firmly grounded the new form of messaging in literature, the authors neither laid out propositions nor made testable predictions regarding how adherence to CERC principles by health communicators was likely to impact target audiences. Ultimately, the overarching nature of the model left it open to critiques of overgeneralization even as it made an efficient tool for training public health professionals. It shares the general weaknesses of stage models that pinpointing with certainty the stage in which one is operating at the time is approximate, extended crises may cycle through stages more than once, and different populations may experience stages at different points in time. CERC has also been specifically criticized for the inability to accommodate events with long maintenance stages (Sellnow \& Seeger, 2013). The COVID-19 pandemic is a case in point. The model provides no explicit guidance for shifting communication needs during a global maintenance phase that is months-long in duration.

In response to this sort of criticism, Veil et al. (2008) published a theory piece about CERC 3 years after Reynolds and Seeger's (2005) original article. They traced the roots of the model in literature on sensemaking and self-efficacy and advanced the following six propositions to be used as a basis for additional validation through future research:

1. risk and crisis are equivocal and uncertain conditions that create specific informational needs and deficiencies;

2. ongoing, two-way communication activities are necessary for the public, agencies, and other stakeholders to make sense of uncertain and equivocal situations and make 
choices about how to manage and reduce the threat to their health;

3. communication processes will change dramatically as a risk evolves through the phases of a crisis, introducing new risks as a crisis evolves to post-crisis and recovery;

4. risk communication messages communicated before a crisis influence perceptions, expectations, and behavior after the crisis erupts. In turn, these crisis responses influence subsequent risk messages;

5. communication is consequential to specific risk and crisis management outcomes by promoting self-efficacy, and

6. risks and crises affect a wide variety of publics with variable needs, interests, and resources which in turn affects their communication capacities, needs, and activities.

The first three propositions emphasize the central, bi-directional, and evolving role of communication in the comprehensive response to crises and emergencies. The remaining propositions stress the importance of considering pre-crisis risk communication (proposition 4), audience self-efficacy (proposition 5), and the diversity of the CERC audiences (proposition 6). Veil et al. (2008) purposed to provide a roadmap for empirical investigation of CERC, however, their propositions, although insightful, serve more to clarify underlying assumptions of the model rather than providing theoretical tenets. Their propositions are either not testable (proposition 1), or not specific enough to generate hypotheses (propositions 2, 3, 4, 5, 6). Vague phrases like "two-way communication," "other stakeholders," "communication processes," "change dramatically," "communication capacities, needs, and activities," "consequential," and "informational needs and deficiencies" cannot be operationalized without extrapolation. Additionally, proposition 3 employs different terms for crisis phases than those presented in the model. Finally, the six principles of emergency and risk communication central to the model as propounded by the CDC-be first, be right, be credible, express empathy, promote action, show respect-are nowhere mentioned.

As a collective expression of the parameters of CERC, the six propositions also fall short of several of the criteria required of 
good theory: predictive power, heuristic provocativeness, and organizing power (Berger \& Chaffee, 1988). Given that the constructs are vague and difficult to operationalize, they have little predictive power. Logical connections between the separate propositions are not articulated and, as a result, they do not provide a coherent structure by which scientific knowledge can be organized. The combination of these factors is likely to cause the theory to be low in heuristic provocativeness; that is, in generating further research and theory building.

In summary, although CERC is theoretically grounded, both in extensive literature and practitioner experience, it does not appear amendable to empirical testing. If we are correct, little research based on CERC should exist. If, however, Veil et al's (2008) propositions have fulfilled their purpose, a systematic pattern of research testing the propositions should be available. In order to determine whether CERC has served as a springboard for empirical research, we posed the following research questions:

RQ1: What type of research has been conducted on CERC?

RQ2: To what extent do systematic research programs associated with CERC exist?

RQ3: To what extent have propositions of the model been tested?

\section{Method}

To answer these questions, we conducted a systematic review of literature. Following Levac et al. (2010), all aspects of the process were iterative and collaborative. Our team consisted of trained undergraduate and graduate students; three researchers with a research focus on risk, crisis, and health communication; and a university librarian.

The systematic review took place in two phases: (1) knowledge mapping to identify primary studies and grey literature reports that map against the research question and make clear the disciplinary and geographical spread of evidence (Clapton et al., 2009); and (2) examination of methodological and theoretical issues for research reports in which CERC served as a key theoretical lens, with particular attention to Veil et al.s (2008) six propositions. 


\section{Data Sources}

Literature review for the knowledge map included searches in 22 academic and grey literature databases between late September and early November 2017. Academic databases searched were: ABI Inform, Academic Search Premier, Applied Social Sciences Indexes and Abstracts (ASSIA), Business Source Premier, CINAHL, Cochrane Central Registry of Controlled Trials, Cochrane Database of Systematic Reviews, Communication and Mass Media Complete (EBSCOhost), ERIC, MEDLINE, PAIS, PsycInfo, Science Direct, Sociological Abstracts, Springer Link, and Web of Science (SSCI, A \& HCI, CPCI-S, BKCI-S, CKSI-SSH, ESCI, CCR databases). In order to ensure broad inclusion of diverse research and locate literature from low- and middle-income countries, we did not restrict the search to specific languages. We also searched Google Scholar and Communication Initiative to identify both academic and grey literature. Additionally, we searched databases in Russian (Russian Science Citation Index), Korean (Korean Journal Database), and Spanish (SciELO; LILACS) which were searchable with English search terms. Altogether records were identified in 19 languages in addition to English (Arabic, 1; Bosnian, 1; Bulgarian, 1; Catalan, 1; Chinese, 7; Croatian, 1; Czech, 3; Dutch, 1; Estonian, 2; French, 5; Finnish, 1; German, 6; Italian, 6; Korean, 11; Lithuanian, 2; Norwegian, 1; Persian, 1; Polish, 1; Portuguese, 10; Romanian, 3; Russian, 1; Spanish, 15; Swedish, 2; Turkish, 2; Ukranian, 2). The date range searched was between 2002 and 2017.

\section{Electronic Search Strategies}

Using a Boolean approach, we searched three realms of subjects in the literature: (1) CERC-related terms, (2) general disaster terminology, and (3) specific crises/disasters/emergencies. Search strategies and terms were tailored for each database with reference to database thesauruses. The majority of databases allowed the terms "Crisis and Emergency Risk Communication" and CERC to be searched both as keywords and as text words to capture those phrases within the entire document text. Additionally, we searched both broad crisis terms and terms related to specific crisis events both as keywords and text words. We allowed selected $\mathrm{MeSH}$ (Medical Subject Headings) to be "exploded" to locate additional 
synonyms and related terms. Grey literature, such as published reports on governmental and nongovernmental websites, was also searched. Table 1 provides a list of search terms. Specific search terms and strategies applied to each database can be obtained from the first author.

Ancestry and forward citation searching were performed on all identified highly relevant articles. To ensure that no articles remained uncaptured, additional subject headings and keywords were derived from articles found through ancestry and forward citation searching. Searches were then re-run including new keywords and subject terms in all databases. A total of 4,471 records were retrieved.

\section{TABLE 1 Search Terms Used}

\begin{tabular}{|c|c|}
\hline $\begin{array}{l}\text { Category of } \\
\text { Search Term }\end{array}$ & Search Terms Used \\
\hline CERC-related & $\begin{array}{l}\text { CDC AND CERC, "Centers for Disease Control and } \\
\text { Prevention","crisis and emergency risk communication", } \\
\text { "crisis emergency and risk communication","crisis } \\
\text { emergency risk communication", CERC, "CERC AND casualt*", } \\
\text { "CERC AND disaster*, "CERC AND emergenc*", "CERC AND } \\
\text { incident*", CERC AND risk\# communicat*, ,CERC AND } \\
\text { Center* for Disease Control" }\end{array}$ \\
\hline $\begin{array}{l}\text { General } \\
\text { disaster }\end{array}$ & $\begin{array}{l}\text { casualt*, catastrophe*, communicat*, crises, crisis, disaster*, } \\
\text { "disaster planning", "disease surveillance", emergenc*, } \\
\text { emergencies, "emergency preparedness*", "mass casualty*, } \\
\text { mass casualty incidents", "natural disaster*", outbreak*, } \\
\text { preparedness, "public health", "relief work", risk, "risk } \\
\text { management*","relief work*", terrorist*, training }\end{array}$ \\
\hline $\begin{array}{l}\text { Specific } \\
\text { disaster }\end{array}$ & $\begin{array}{l}\text { anthrax, "biological agent", "biological warfare," bioterror*, } \\
\text { "chemical agent*", "chemical warfare", "chemical warfare } \\
\text { agents", "communicable disease*", catastrophe*, cyclone*, } \\
\text { disaster*, drought, earthquake*, ebola*, "ebola virus", } \\
\text { epidemic* , famine*, fires, flood*, flu, food, "food poisoning", } \\
\text { health, or hospital, H1N1, "hemorrhagic fever", hurricane*, } \\
\text { immuniz*, influenza, "influenza A virus", nuclear, "nuclear } \\
\text { power plants", "nuclear reactors", "nuclear war", pandemic, } \\
\text { plague, SARS, "SARS virus", Severe Acute Respiratory } \\
\text { Syndrome, spill\#, spill, spills, terroris*, tornado, vaccinat*, } \\
\text { virus*, volcano*, and Zika. }\end{array}$ \\
\hline
\end{tabular}




\section{Study Screening Method}

The article selection process took place in several stages as displayed via a PRISMA flow diagram in Figure 1. After duplicates were removed and articles were title screened by two team members working independently, 1,184 distinct records remained. (For ambiguous cases, decisions were made through discussion to consensus.) Full texts of all these documents were judged for relevance by two team members, with full texts for six articles not located. After examination, 778 full texts were excluded because they did not meet inclusion and exclusion criteria (see below). The remaining 400 articles were selected for extraction of key findings for the knowledge map in phase 1. Papers that included original research reports (e.g., not opinion pieces or general essays) in which CERC was identified as playing a central role were analyzed in phase 2 .

\section{Inclusion and Exclusion Criteria}

Articles were considered to satisfy inclusion criteria if they mentioned "Crisis and Emergency Risk Communication" and/or CERC specifically in the main text of the document. Articles in which CERC was an abbreviation for something other than Crisis and Emergency Risk Communication, or in which CERC or Crisis and Emergency Risk Communication or Crisis Emergency and Risk Communication was mentioned only in a footnote, appendix, or references list were excluded.

\section{Data Extraction}

After the research team jointly developed and tested a coding scheme, each article was coded for key descriptive characteristics by two team members working individually. Disagreements in coding were resolved by senior members of the research team. The following categories were coded: field of inquiry of first author; nationality of the first author's institution or organization; nation the article was about; type of document (i.e., research article, essay, descriptive case study, or other); crisis type (i.e., bioterrorism, terrorism, drought, earthquake, flood, infectious diseases, nuclear, radiological or chemical incidents, weather-related crises like tornados and hurricanes, wildfires, general crisis, or other articles); and whether CERC was a central focus of the article. 


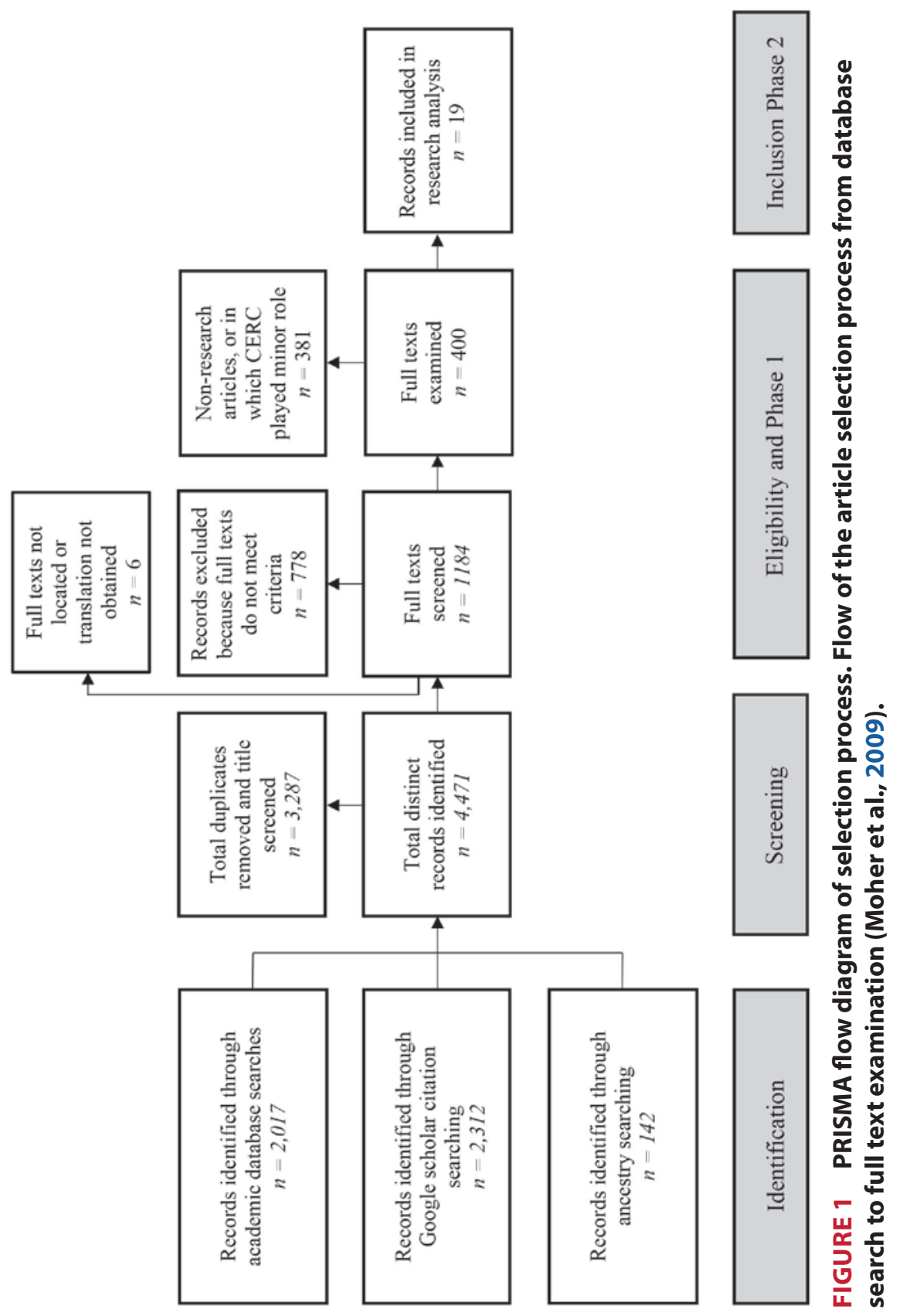


In the second phase of analysis, research articles in which CERC was identified as playing a central role were subjected to more in-depth examination of methodological and theoretical characteristics. Documents were coded in line with the SPICE framework for question formulation (Booth, 2006): setting (nation; captured in phase I), perspective (sample identity and size, e.g., general population, first responders, county health officers), type of intervention (media channel; crisis phase), comparison (comparison group or not; captured in research method), evaluation (research method used, i.e., experiment, cross-sectional survey, longitudinal survey, focus groups, qualitative interviews, content analysis, observation, simulation, other). Narrative literature reviews were not counted as research. We also coded whether the research was funded (and if so by whom) and whether any of Veil et al.s (2008) six propositions were empirically tested.

\section{Results}

\section{Phase 1: Key Characteristics of Identified Documents}

Key descriptive characteristics of the studies are presented in Table 2. The two fields in which CERC was most frequently applied were the fields of the respective authors of its first formal introduction: public health (Reynolds) and communication (Seeger). It has also been used with some frequency in emergency management, medicine and nursing, and business. Nearly two-thirds of first authors were located at North American institutions, and the bulk of the remainder were at European institutions. A few authors at Asian institutions have written about the model, but authors from the Pacific, Latin America/Caribbean, and especially African regions were rare. Similarly, the largest numbers of specific crises studied took place in North America, followed by Europe. A substantial portion of the articles were location-generic, that is, they discussed broad principles of crisis and risk communication.

Regarding the type of crisis to which the CERC model has been applied, nearly half of articles identified were crisis general. Of those that addressed specific types of crises, by far the most common was infectious diseases. Weather-related crises and drought, as well as terrorist and bioterrorist incidents were also addressed. 
We also note that certain authors appear with regularity among the articles, either as authors or as supervisor on dissertations. In addition to Reynolds and Seeger, Lachlan, Liu, Quinn, T. Sellnow, Spence, and Veil were each author on at least five articles. Several of these individuals were involved in initial conceptualization, proposition development, and testing of the model.

\section{TABLE 2 Key Characteristics of Identified Documents}

\section{Discipline of First Author}

Business/Management: 15

Medical/Nursing/Sciences: 34

Communication: 141

Health/Health Education/Public

Health: 127

Emergency Management/Safety/

Security: 16

\section{Location of First Author's Institution}

Africa: 1

Asia: 20

Europe: 118

Latin America/Caribbean: 8
Social Sciences: 28

Engineering/Computer Science: 6

Other (e.g., Education, Hospitality): 17

Law/Politics/Politics: 10

Unable to determine: 6

\section{Region of Crisis/Disaster}

Africa: 2

Asia: 25

Middle East: 10

North America: 236

Pacific: 5

Unable to determine: 2

Europe: 81

Middle East: 5

North America: 202

Pacific: 5

Latin America/Caribbean: 12

Generic/Multiple: 68

\section{Type of Crisis/Disaster}

Bioterrorism: 11

Drought: 13

Earthquake: 7

Flood: 6

Infectious diseases: 127

Nuclear: 5

Terrorism: 12

Weather (e.g., hurricane, tornado, typhoon): 13

Wildfires: 4

General: 167

Other (e.g., food, volcano, water): 12

Radiological or chemical incident: 13 Uncertain: 10

\section{Type of Article}

Research Report: 172

Essay: 156

Case study: 60

Other (e.g., presentations and proceedings): 12

\section{Role of CERC in Article}

Minimal: 299

Major: 101 


\section{Phase 2: Characteristics of Research in Which CERC Played a Central Role}

RQ1 asked what type of research has been conducted on CERC. Among the 400 articles selected for inclusion, 19 satisfied criteria for further analysis in phase 2: (1) being research reports, and (2) assigning a central role to CERC. Characteristics of these articles are presented in Table 3. Among these studies, the most frequently used research methods were qualitative interviews with stakeholders (seven instances; one of these also used focus group discussions) and content analysis (seven instances). Typically, content analytic studies compared aspects of news coverage and social media releases about a specific crisis to CERC message construction guidelines for each crisis phase. Four studies employed experimental designs. One use of survey and one simulation were identified. As with the larger pool of articles identified in phase 1, the vast majority of the studies that investigated CERC in depth were undertaken in North America and Europe. Approximately one-fourth of the studies were funded, with funds supplied by a range of governmental agencies and institutions in the United States and Europe. Four of the studies were theses or dissertations.

$\mathrm{RQ} 2$ asked to what extent systematic research programs were associated with CERC. No researcher appeared as author or thesis/ dissertation supervisor on more than one of the 19 articles in which CERC was a major focus, indicating it was not the subject of any systematic research program.

RQ3 asked to what extent propositions of the model had been tested. Only one of the 19 studies explicitly tested the CERC propositions identified by Veil and colleagues (2008): Aerts (2013). The Aerts study is a master's thesis completed at the University of Twente. The research was a $2 \times 2$ between-subjects experiment which manipulated stage of crisis and efficacy beliefs in risk messaging on perceived threat, efficacy, information seeking, and self-protective behavior in a sample of the general Dutch population. In line with CERC predictions, both perceived efficacy as well as perceived threat were associated both with information seeking and protective behavior. Other experimental studies presented CERC as a broad foundational framework, but investigated 


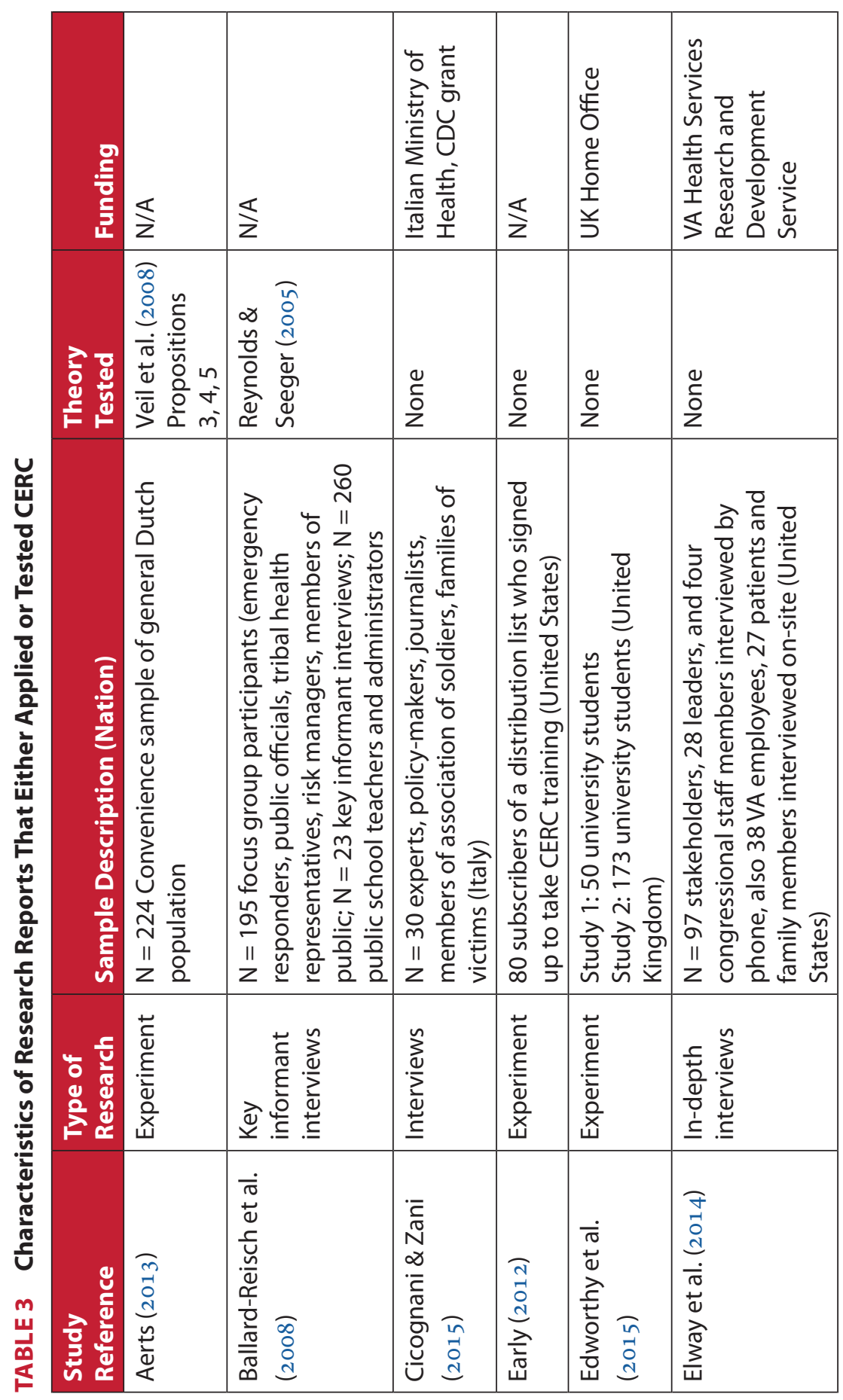




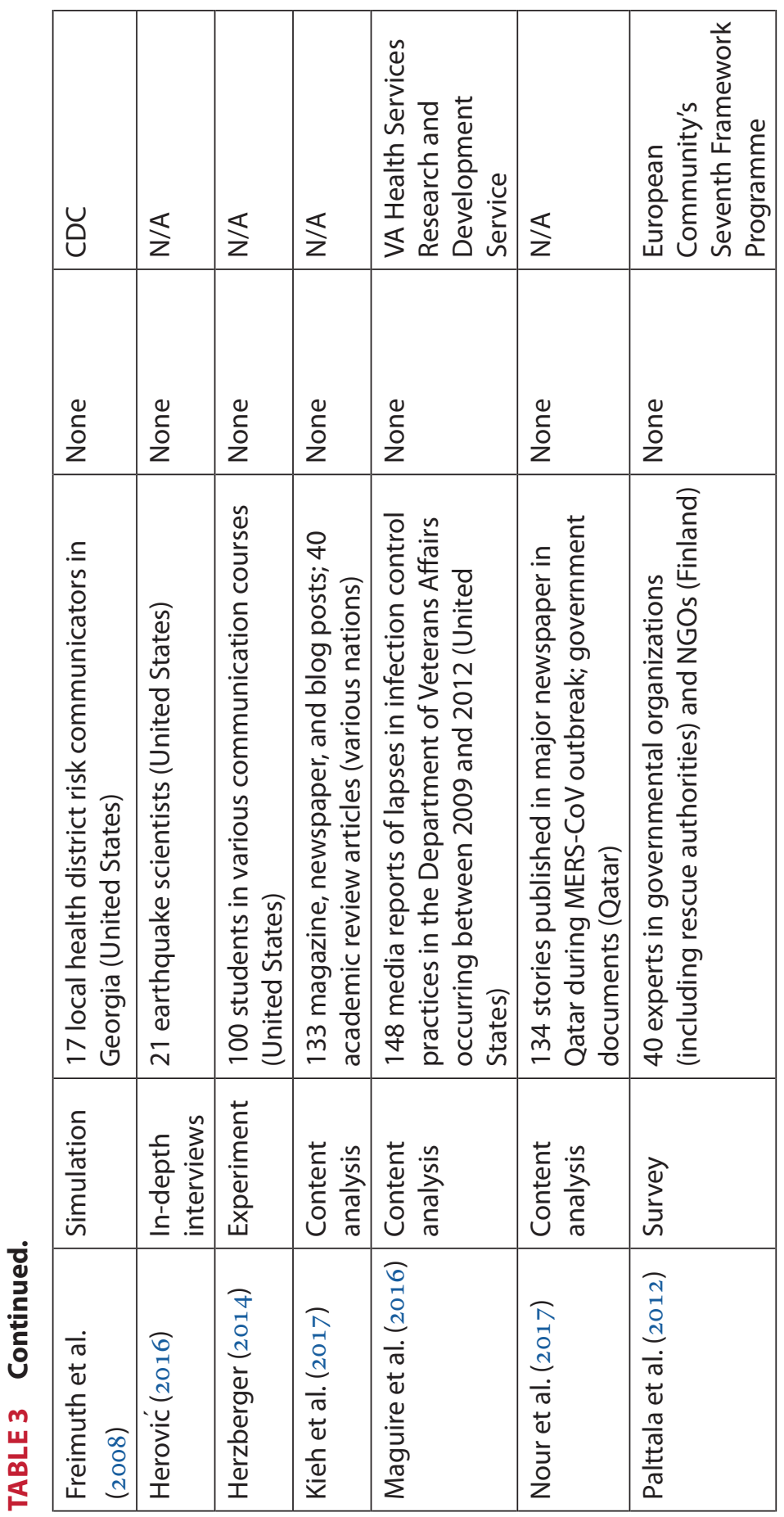




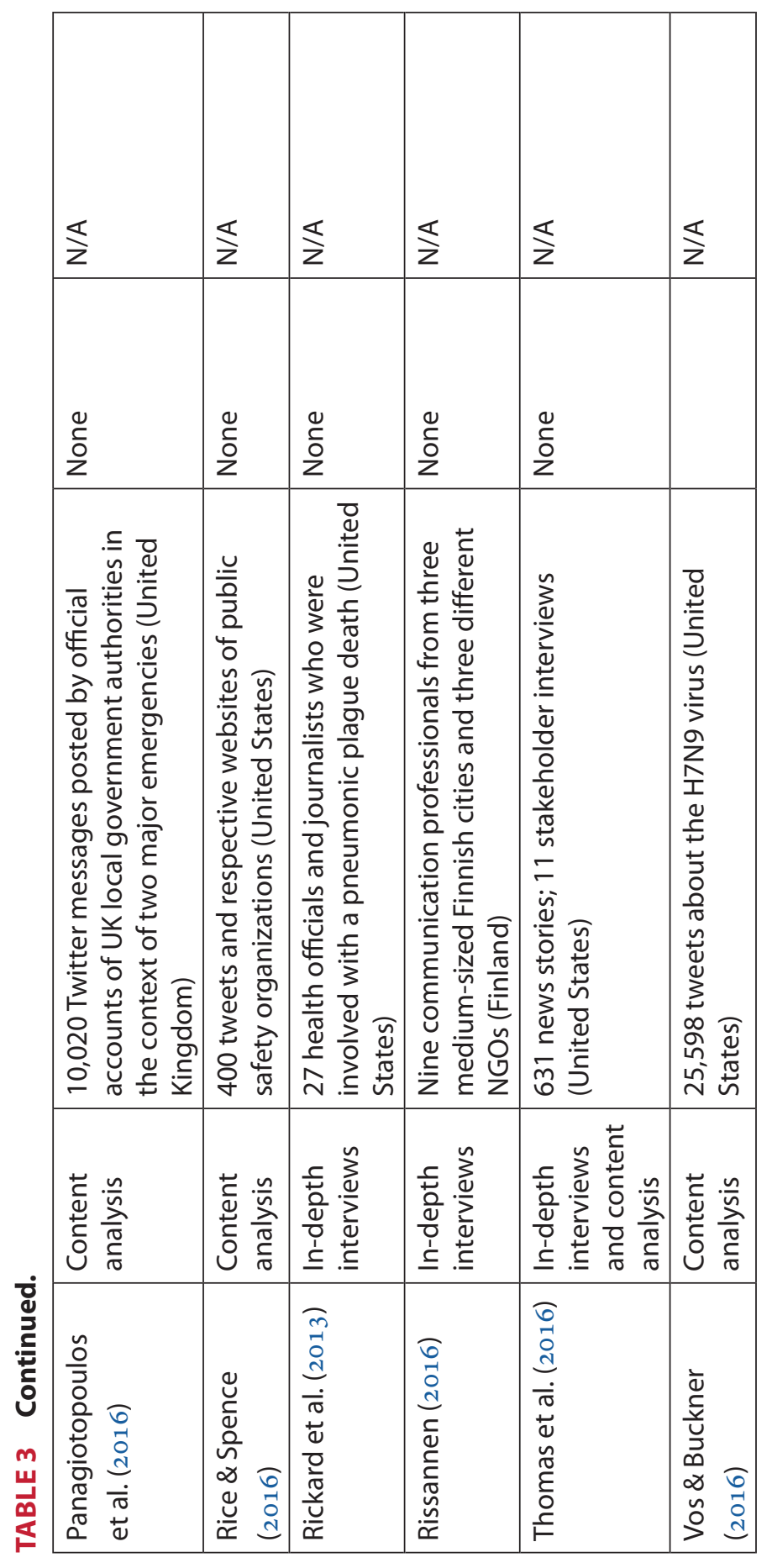


a narrow slice of crisis communication. Edworthy et al. (2015) manipulated communication channel, information type, and repetition to determine influences on accuracy of message transmission in early stages of a crisis. Herzberger (2014) focused on predictions of CERC regarding source credibility and organizational reputation. Only Aerts's study attempted a comparison of crisis messaging between phases.

Among the other 16 research reports in which CERC played a major role, a large portion used CERC principles as presented in the CERC Manual to evaluate adequacy of news coverage, tweets, and other public health responses during a specific crisis (Kieh et al., 2017; Maguire et al., 2016; Nour et al., 2017; Ophir, 2018; Panagiotopoulos et al., 2016; Thomas et al., 2016). For example, Maguire and colleagues developed a coding scheme based on the CERC Manual and evaluated the extent to which certain components of effective communication were more present than others in Department of Veterans Affairs infection control lapse incidents between 2009 and 2012. Freimuth et al. (2008) designed a 4-hour simulation based on CERC principles in which 17 local health district risk communicators in Georgia were assessed with respect to their adherence to risk communication guidelines under time pressure. Qualitative studies largely addressed the same topics. Cicognani \& Zani (2015) and Elway et al. (2014) investigated communication through phases of a crisis via retrospective interviews of crisis communication or emergency response personnel. Herović (2016) and Rissanens (2016) conducted individual in-depth interviews about characteristics of effective communication within the pre-crisis phase.

\section{Discussion}

CERC was first formulated nearly 20 years ago and published for academic audiences 15 years ago. It has, to all appearances, been highly useful as a tool for practitioners (US Department of Health and Human Services [HHS] and CDC, 2018). Indeed, the model has largely served the purpose for which it was originally created. Until now, however, it has not been clear whether CERC has also served to generate research that goes beyond existing best practices 
to add knowledge, predictive and testable in nature, about crisis communication in public health emergencies. Findings of this systematic review indicate that although a robust body of research has cited and applied the CERC model in case studies, few projects have empirically tested CERC.

This state of affairs is consistent with the general situation in disaster preparedness literature. Scholars have repeatedly concluded that evaluation efforts are usually not scientifically rigorous (Jose \& Dufrene, 2014; Miller et al., 2017; Nour et al., 2017; Williams et al., 2008). Methods used for evaluation have been found to be heterogeneous and often not well-described (Beerens \& Tehler, 2016), few standardized assessment tools exist (Gallardo et al., 2015), and control groups are rarely used (Williams et al., 2008). Like CERC, research on crisis communication training more broadly has been found to focus overwhelmingly on crises in Western nations (Miller et al., 2017). Many of these limitations stem from the fact that disaster communication research is often applied in nature and seeks to retrospectively understand how and why communication strategies employed during the crisis were or were not successful.

Nevertheless, an opportunity exists to further refine CERC in a way that advances scholarly work in the area and increases the utility of the model for practical application. A systematic review cannot definitively determine why something has not been empirically tested. However, the fact that a large proportion of the investigations of CERC consist of content analyses of news coverage through stages of crises (Kieh et al., 2017; Maguire et al., 2016; Nour et al., 2017; Ophir, 2018; Panagiotopoulos et al., 2016; Thomas et al., 2016) suggests that researchers have found the stage elements of the model more useful in highly applied settings as a standard for retrospective critique than as a predictive tool about the outcomes of that messaging. Furthermore, all of these studies assessed news coverage over the life of a crisis by comparing them to CERC as presented in CDC publications like the CERC Manual (U.S. Department of Health and Human Services [HHS] and CDC, 2018), rather than measuring against Veil et al.s (2008) formal propositions. 
Only one experimental study we located attempted to compare communication within different stages of a crisis: Aerts (2013). The same study was the only one to test any of Veil et al.s (2008) propositions. Other experimental studies investigating CERC have focused on relationships between characteristics of crisis communication and outcomes in members of the public (Edworthy et al., 2015; Herzberger, 2014). In that sense, they are consonant with the emphasis of the six principles in the CERC Manual (U.S. Department of Health and Human Services [HHS] and CDC, 2018).

Based on this analysis, we conclude that although CERC is theoretically grounded, its contribution could be extended if it were presented in a different form. To reach this potential, the model should be formatted so as to include testable statements predicting relationships between characteristics of communication (timeliness, accuracy, source credibility, empathy, action-orientation, and respect) and audience outcomes (e.g., uncertainty reduction, self-efficacy) identified in the CERC Manual. These statements need to be parsimonious, but collectively provide a coherent structure by which knowledge can be organized (Berger \& Chaffee, 1988).

Figure 2 presents a straightforward graphic depiction of the relationships described in CERC that can be used to generate a range

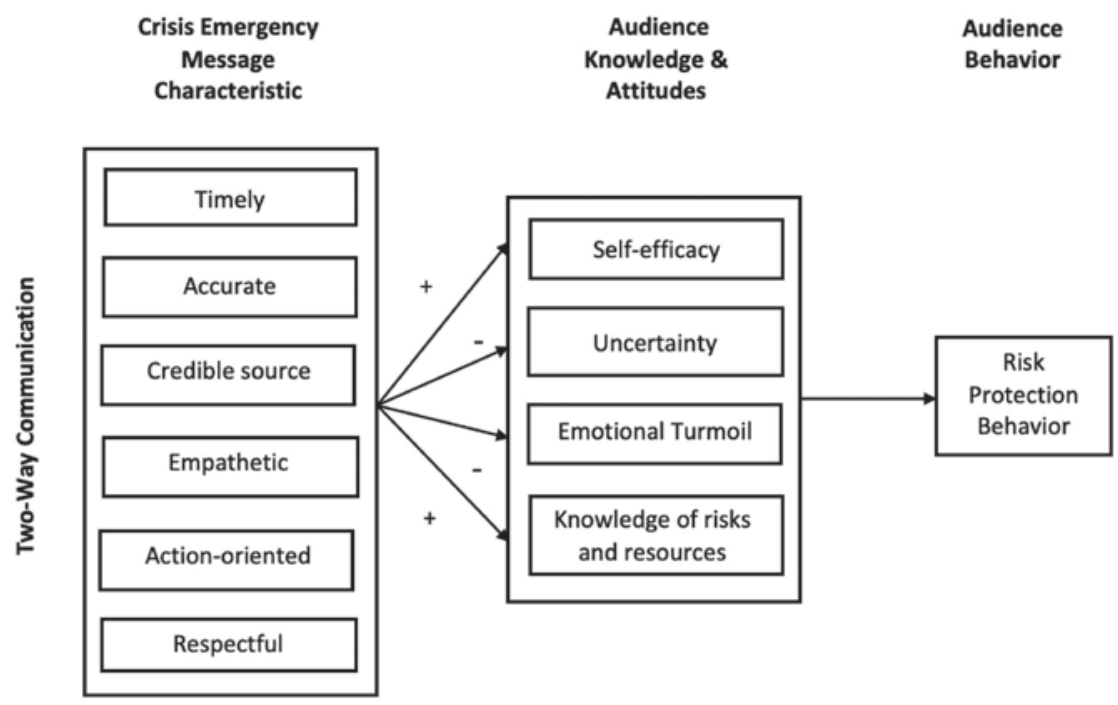

FIGURE 2 Graphic Representation of CERC Principles 
of testable hypotheses (U.S. Department of Health and Human Services [HHS] and CDC, 2018). All six message characteristics (timeliness, accuracy, credibility, empathy, action-orientation, and respect) are positively associated with self-efficacy and knowledge, and negatively associated with uncertainty and emotional turmoil. In turn, self-efficacy and knowledge are positively associated, and uncertainty and emotional turmoil negatively associated, with the ultimate goal of risk protective behavior among audience members. Two-way communication with stakeholders functions as an antecedent variable, enabling health communicators to shape essential characteristics of messages more effectively. Predictive statements can be derived by tracing the causal paths of the model, thus providing a coherent structure for organizing resultant knowledge. Predictions can be tested within the parameters of any crisis stage and readily lend themselves to experimental research. By clearly articulating such predictive statements, applications of the CERC model can move beyond case studies to include simulations and experiments that align message testing with the various stages of the model. The resulting research would address the need for rigorous message testing in disaster preparedness described above (Jose \& Dufrene, 2014; Miller et al., 2017; Nour et al., 2017; Williams et al., 2008).

\section{Limitations and Conclusion}

Though guided by rigorous systematic review protocols, this work was limited in several ways. First and most importantly, literature may have been missed in our searches. Though one of the authors is a librarian with extensive experience in systematic reviews, some work may have been overlooked. In particular, the bulk of the literature examined was also in English and although several non-English language databases were searched there may be relevant scholarly work in other languages we did not uncover. Additionally, coding protocols relied on expert coding and resolution of inconsistencies through discussion which precluded traditional measures of inter-coder reliability.

In conclusion, with thousands of references uncovered and likely thousands more unpublished applications of the work in the field, the current study clearly demonstrated CERC is widely 
applied across risk and crisis contexts. However, rigorous theory-guided empirical investigations of CERC are largely absent. We have provided a broad overview of existing scholarship and a proposed framework with clear direction for further CERC development and contributions. CERC has demonstrated robust scope and explanatory power, and with increased focus on ensuring testable formal development building on knowledge gained from this systematic review, it is likely CERC can additionally generate theory testing and new knowledge of crisis and risk communication.

\section{ORCID}

Ann Miller (i) https://orcid.org/o0oo-0002-0710-2056

Timothy Sellnow (1) https://orcid.org/oooo-0001-5353-4629

\section{References from Studies Applying or Testing CERC}

Aerts, S. (2013). Applying the CERC model within the context of extreme weather: A study about the influence of the timing and efficacy beliefs on information seeking and self-protective behaviors. Master's thesis. University of Twente.

Anthony, K. E., \& Sellnow, T. L. (2011). "Information acquisition, perception, preference, and convergence by Gulf Coast residents in the aftermath of the Hurricane Katrina crisis." Argumentation and Advocacy, 48, 81-96. https://doi.org/10.1 080/00028533.2011.11821756

Ballard-Reisch, D., Clements-Nolle, K., Jenkins, T., Sacks, T., Pruitt, K., \& Leathers, K. (2008). Applying the crisis and emergency risk communication (CERC) integrative model to bioterrorism preparedness: A case study. In M. W. Seeger, T. L. Sellnow, \& R. R. Ulmer (Eds.) Crisis communication and the public health (pp. 203-220). Hampton Press.

Cicognani, E., \& Zani, B. (2015). Communication of health risks from exposure to depleted uranium (DU) in Italy: A case study. Journal of Risk Research, 18, 771-788. https://doi.org/10.1080/ 13669877.2014 .913657 
Early, E. A. (2012). Effectiveness of virtual worlds in public health preparedness training. Dissertation for Capella University.

Edworthy, J., Hellier, E., Newbold, L., \& Titchener, K. (2015). Passing crisis and emergency risk communications: The effects of communication channel, information type, and repetition. Applied Ergonomics, 48, 252-262. https://doi.org/10.1016/j. apergo.2014.12.009

Elway, A. R., Bokhour, B. G., Maguire, E. M., Wagner, T. H., Asch, S. M., Gifford, A. L., Gallagher, T. H., Durfee, J. M., Martinello, R. A., Schiffner, S., \& Jesse, R. L. (2014). Improving healthcare systems' disclosures of large-scale adverse events: A Department of Veterans Affairs leadership, policymaker, research and stakeholder partnership. JGIM: Journal of General Internal Medicine, 29, 895-903. https://doi.org/10.1007/s11606-014-3034-3

Freimuth, V. S., Hilyard, K. M., Barge, J. K., \& Sokler, L. A. (2008). Action, not talk: A simulation of risk communication during the first hours of a pandemic. Health Promotion Practice, 9(4 Suppl), 35S-44S. https://doi.org/10.1177/1524839908322111

Herović, E. (2016). The challenges of communicating a low probability and high consequence risk: Recommendations for earthquake pre-crisis and emergency-risk communication (Unpublished master's thesis). University of Kentucky.

Herzberger, J. D. (2014). "Can you hear me now?": Experimental research on the efficacy of pre-crisis messages in a severe weather context (Unpublished master's thesis). Cleveland State University.

Kieh, M. D., Cho, E. M., \& Myles, I. A. (2017). Contrasting academic and lay press print coverage of the 2013-2016 Ebola Virus Disease outbreak. Plos One, 12, 1-33. https://doi. org/10.1371/journal.pone.0179356

Maguire, E. M., Bokhour, B. G., Asch, S. M., Wagner, T. H., Gifford, A. L., Gallagher, T. H., Durfee, J. M., Martinello, R. A., \& Elwy, A. R. (2016). Disclosing large scale adverse events in the US Veterans Health Administration: Lessons from media responses. Public Health, 135, 75-82. https://doi.org/10.1016/j. puhe.2015.10.016 
Nour, M., Alhajri, M., Farag, E. A. B. A., Al-Romaihi, H. E., Al-Thani, M., Al-Marri, S., \& Savoia, E. (2017). How do the first days count? A case study of Qatar experiment in emergency risk communication during the MERS-CoV outbreak. International Journal of Environmental Research and Public Health, 14, 15971612. https://doi.org/10.3390/ijerph14121597

Ophir, Y. (2018). Coverage of Epidemics in American newspapers through the lens of the crisis and emergency risk communication framework. Health Security, 16, 147-157. https://doi. org/10.1089/hs.2017.0106

Palttala, P., Boano, C., Lund, R., \& Vos, M. (2012). Communication gaps in disaster management: Perceptions by experts from governmental and non-governmental organizations." Journal of Contingencies \& Crisis Management, 20, 2-12. https://doi. org/10.1111/j.1468-5973.2011.00656.x

Panagiotopoulos, P., Barnett, J., Bigdeli, A. Z., \& Sams, S. (2016). Social media in emergency management: Twitter as a tool for communicating risks to the public. TechnologicalForecastingand Social Change, 111, 86-96. https://doi.org/10.1016/j.techfore .2016 .06 .010

Rice, R. G., \& Spence, P. R. (2016). Thor visits Lexington: Exploration of the knowledge-sharing gap and risk management learning in social media during multiple winter storms. Computers in Human Behavior, 65, 612-618. https://doi. org/10.1016/j.chb.2016.05.088

Rickard, L. N., Mccomas, K. A., Clarke, C. E., Stedman, R. C., \& Decker, D. J. (2013). Exploring risk attenuation and crisis communication after a plague death in Grand Canyon. Journal of Risk Research, 16, 145-167. https://doi.org/10.1080/13669877 .2012 .725673

Rissannen, M. (2016). Crisis preparedness through co-operation between municipalities and non-governmental organizations. Unpublished master's thesis. University of Jyväskylä. 
Thomas, T. L., Kannaley, K., Friedman, D. B., Tanner, A. H., Brandt, H. M., \& Spencer, S. M. (2016). Media Coverage of the 2014 West Virginia Elk River chemical spill: A mixedmethods study examining news coverage of a public health disaster. Science Communication, 38, 574-60o. https://doi. org/10.1177/1075547016662656

Vos, S. C., \& Buckner, M. M. (2016). Social media messages in an emerging health crisis: Tweeting bird flu. Journal of Health Communication, 21(3), 301-308. https://doi.org/10.1080/1081 0730.2015 .1064495

\section{References}

Anthony, K. E., \& Sellnow. T. L. (2011). Information acquisition, perception, preference, and convergence by Gulf Coast residents in the aftermath of the Hurricane Katrina crisis. Argumentation and Advocacy, 48, 81-96.

Barge, J. K., \& Craig, R. T. (2009). Practical theory in applied communication scholarship. Routledge handbook of applied communication research, 55-78.

Beerens, R. J. J., \& Tehler, H. (2016). Scoping the field of disaster exercise evaluation-A literature synthesis. International Journal of Disaster Risk Reduction, 19, 413-446. https://doi. org/10.1016/j.ijdrr.2016.09.001

Berger, C. R., \& Chaffee, S. H. (1988). On bridging the communication gap. Human Communication Research, 15(2), 311-318.

Booth, A. (2006). Clear and present questions: Formulating questions for evidence-based practice. Library Hi Tech, 24, 355368. https://doi.org/10.1108/07378830610692127

Clapton, J., Rutter, D., \& Sharif, N. (2009). SCIE systematic mapping guidance. London: SCIE.

Elledge, B. L., Brand, M., Regens, J. L., \& Boatright, D. T. (2008). Implications of public understanding of avian influenza for fostering effective risk communication. Health Promotion Practice, 9, 54S-59S. https://doi.org/10.1177/1524839908319089 
Fink, S. (1986). Crises management: Planning for the inevitable. American Management Association.

Gallardo, A. R., Djalali, A., Foletti, M., Ragazzoni, L., Corte, F. D., Lupescu, O., Arculeo, C., von Arnim, G., Friedl, T., Ashkenazi, M., Fisher, P., Hreckovski, B., Khorram-Manesh, A., Komadina, R., Lechner, K., Stal, M., Patru, C., Burkle Jr., F. M., \& Ingrassia, P. L. (2015). Core competencies in disaster management and humanitarian assistance: A systematic review. Disaster Medicine and Health Preparedness, 9, 430-439. https://doi.org/10.1017/ dmp.2015.24

Jose, M. M., \& Dufrene, C. (2014). Educational competencies and technologies for disaster preparedness in undergraduate nursing education: An integrative review. Nurse Education Today, 34, 543-551. https://doi.org/10.1016/j.nedt.2013.07.021

Levac, D., Colquhoun, H., \& O’Brien, K. K. (2010). Scoping studies: Advancing the methodology. Implementation Science, 5, 69-77. https://doi.org/10.1186/1748-5908-5-69

Miller, A. N., Sellnow, T., Neuberger, L., Todd, A., Freihaut, R., Noyes, J., Allen, T., Alexander, N., Vanderford, M., \& Gamhewage, G. (2017). A systematic review of literature on training in crisis and risk preparedness. Journal of Health Communication, 22, 612-629. https://doi.org/10.1080/108107 30.2017 .1338802

Moher, D., Liberati, A., Tetzlaff, J., Altman, D. G., \& The PRISMA Group. (2009). Preferred reporting items for systematic reviews and analyses: The PRISMA statement. Plos Medicine, 6, e1000097. https://doi.org/10.1371/journal.pmed.1000097

Reynolds, B., \& Quinn, S. C. (2008). Effective communication during an influenza pandemic: The value of using a crisis and emergency risk communication framework. Health Promotion Practice, 9(4 Suppl), 13S-17S. https://doi. org/10.1177/1524839908325267

Reynolds, B., \& Seeger, M. W. (2005). Crisis and emergency risk communication as an integrative model. Journal of Health Communication, 10(1), 43-55. https://doi. org/10.1080/10810730590904571 
Sellnow, T. L., \& Seeger, M. W. (2013). Theorizing crisis communication. Wiley-Blackwell.

Turner, B. M. (1967). The organizational and inter-organizational development of disasters. Administrative Science Quarterly, 21, 378-397. https://doi.org/10.2307/2391850

U.S. Department of Health and Humans Services and Centers for Disease Control and Prevention. (2018). CERC: Crisis + Emergency Risk Communication. https://web.archive.org/ web/20200518215809/https://emergency.cdc.gov/cerc/ppt/ CERC_Introduction.pdf

Veil, S., Reynolds, B., Sellnow, T. L., \& Seeger, M. W. (2008). CERC as a theoretical framework for research and practice. Health Promotion Practice, 9(4 Suppl), 26S-34S. https://doi. org/10.1177/1524839908322113

Williams, N., Nocera, M., \& Casteel, C. (2008). The effectiveness of disaster training for healthcare workers: A systematic review. Disaster Medicine, 52, 211-224. https://doi.org/10.1016/j. annemergmed.2007.09.030 

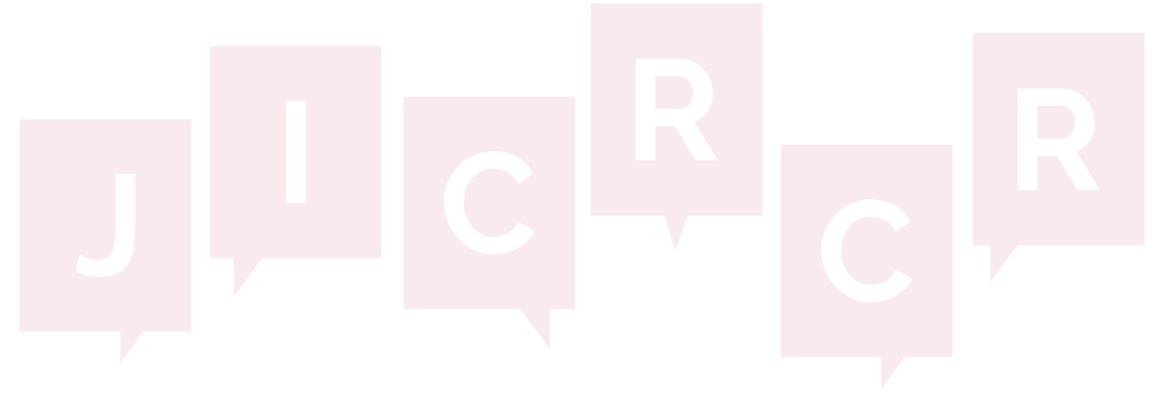